\title{
Chronic pain and fatigue: timescale, feedback, and overrides
}

Buckley, Ralf Christopher

\section{Letter to Editor:}

Chronic pain causes chronic fatigue, through various physiological and psychological mechanisms. ${ }^{9}$ In addition to neurology and biochemistry, pain and fatigue can be studied ethnographically, as sensations perceived by the individual experiencing them. ${ }^{11}$ For some researchers, this includes autoethnography, analysing one's own experience. ${ }^{1,3,7}$ Using that approach, I propose 3 additions to the research agenda set by Van Damme et al.

Relevant technical characteristics, for autoethnographic analysis of chronic pain, are as follows. Origins: impacts from car accidents, falls, etc, over several decades, most recently September 2016. Physiology (computed tomography, magnetic resonance imaging, etc): protrusion and ultimate loss of L5/S1 lumbosacral disk; crushing of the spinal cord and exiting lateral nerves; and compression of several cervical vertebrae. Symptoms: pain, paresthesia, and intermittent loss of function in distal portions of limbs. Duration: several decades, continuous. Intensity: varies. Lowest: dull ache, cf. arthritis. Highest: consumes entire attention, cf. severe cramp or crushed finger; can persist at this intensity for hours. Worsens when seated, improves when lying flat; hinders and interrupts sleep. Exercise, movement, and activities: continued despite pain, but subject to considerable functional limitations. Current age: 64.

Comparing the psychological theories in the recent review, ${ }^{9}$ autoethnographic experience supports resource rather than ego depletion or hyperaversion. ${ }^{5,10}$ Pain and fatigue are messages from the body to the brain. Fatigue indicates a need for rest and recovery. Pain indicates injury. Responses that reduce pain also reduce injury. Pain aversion is adaptive. $., 8,10$ Overriding pain through "executive function," or ignoring pain through pride or pretence, produces more severe and prolonged pain and damage. These are not adaptive. Since autoethnography is individualised research, however, it cannot exclude any specific theory.

The main strength of autoethnography is in adding new insights and hypotheses, depth rather than breadth. I propose 3 additions to any generalised model of chronic pain and fatigue. (1) Timescale: At decadal timescales, reduced exercise capabilities have led to reduced core muscle strength, which increases pain and fatigue. At hourly timescales, high-intensity pain forces rest, to alleviate pain, not through muscular tiredness. (2) Feedback: Physically, continued action despite pain leads to loss of function and flexibility, increasing the likelihood of further injury and longer-lasting pain. One 
therefore learns to identify thresholds and trigger points, to avoid incapacitation. Psychologically, pain creates negative emotions, ${ }^{4}$ and intense pain supersedes all other sensations or emotions. Temporary removal of pain produces (equally temporary) euphoria and energy, irrespective of other circumstances. ${ }^{2}$ There is thus a strong psychological feedback through emotional state. (3) Overrides: Pain can be overcome temporarily through adrenaline. Adrenaline-generating activities are heavily restricted through physical injury and pain, but where possible, cause temporary cessation of pain. This is not merely distraction ${ }^{6}$ : it persists even with deliberate attention to the locus of chronic pain. By generating euphoria, this pain override renders adrenalin activities, particularly addictive. ${ }^{2}$ The same may apply for opioid painkillers.

In conclusion, an autoethnographic approach supports the research priorities proposed, ${ }^{1}$ but adds aspects which may prove equally critical. Unless timescale, feedback, and overrides are considered explicitly, a model relying solely on a calculus of positives and negatives may prove too simplistic to understand, predict, and treat chronic pain sufferers.

\section{References}

[1]. Buckley RC. Autoethnography helps analyse emotions. Front Psych 2015;6:209.

[2]. Buckley RC. Adventure thrills are addictive. Front Psych 2015;6:1915.

[3]. Buckley RC. Qualitative analysis of emotions: fear and thrill. Front Psych 2016;7:1187.

[4]. Craig A, Tran Y, Siddall P, Wijesuriya N, Lovas J, Bartrop R, Middleton J. Developing a model of associations between chronic pain, depressive mood, chronic fatigue, and self-efficacy in people with spinal cord injury. J Pain 2013;14:911-20.

[5]. Crombez G, Eccleston C, Van Damme S, Vlaeyen JWS, Karoly P. The fear-avoidance model of chronic pain: the next generation. Clin J Pain 2012;28:475-83.

[6]. Legrain V, Van Damme S, Eccleston C, Davis KD, Seminowicz DA, Crombez G. A neurocognitive model of attention to pain: behavioral and neuroimaging evidence. PAIN 2009;144:230-2.

[7]. Lipska BK, McArdle E. The neuroscientist who lost her mind. Boston:Houghton Mifflin Harcourt, 2018.

[8]. Van Damme S, Kindermans H. A self-regulation perspective on avoidance and persistence behaviour in chronic pain: new theories, new challenges? Clin J Pain 2015;31:115-22.

[9]. Van Damme S, Becker S, Van der Linden D. Tired of pain? Toward a better understanding of fatigue in chronic pain. PAIN 2018;159:7-10.

[10]. Vlaeyen JWS, Linton SJ. Fear-avoidance model of chronic musculoskeletal pain: 12 years on. PAIN 2012;153:1144-7.

[11]. Wiech K. Deconstructing the sensation of pain: the influence of cognitive processes on pain perception. Science 2016;354:584-7. 